\title{
Adult liver transplantation using pediatric donor livers after cardiac or brain death: A report of three cases
}

\author{
LIMIN DING $^{1}$, LISHAN DENG ${ }^{2}$, XINCHANG LI ${ }^{1}$ and ZHIDAN XU ${ }^{1}$ \\ ${ }^{1}$ Department of Transplantation, Jiangxi Provincial People's Hospital Affiliated to Nanchang University; ${ }^{2}$ Secretarial Section, \\ Jiangxi Provincial Cultural and Sports Management Center for the Disablede, Nanchang, Jiangxi 330000, P.R. China
}

Received August 25, 2019; Accepted May 1, 2020

DOI: 10.3892/etm.2020.9155

\begin{abstract}
The present study reports on the experience at Jiangxi Provincial People's Hospital (Nanchang, China) with liver transplantation in adults using pediatric donor livers, including indications, technique and results. A total of three cases of liver transplantation performed between April 2008 and May 2016 were retrospectively reviewed. Liver procurement and trimming, recipient selection, surgical tips, prevention and treatment of small-for-size syndrome, selection of immunosuppressive regimens, prevention and treatment of vascular complications and anticoagulant therapy were discussed. The three pediatric donors were 8,8 and 10 years old. The three recipients were confirmed to have primary liver cancer. In recipient 1 (female; age, 39 years), jaundice persisted in the recipient after the liver transplantation. A reduced dose of FK506 was then given to gradually decrease the total bilirubin level to the normal range. Recipient 1 recovered and was discharged from hospital; however, the patient died of liver cancer recurrence and bone metastasis 6 years post-transplantation. In recipient 2 (male; age, 56 years), the recipient experienced sudden abdominal distension on postoperative day 7 . The patient's clotting time was prolonged and the transaminase level was sharply increased, peaking on day 9. The patient was suspected of having small-for-size syndrome and was treated symptomatically. The patient experienced a significant improvement in symptoms on postoperative day 13 and regular postoperative follow-ups were performed until now and the patient is now in remission. In recipient 3 (male; age, 48 years), the recipient recovered well and the liver function returned to normal on postoperative day 3 . The patient was discharged from hospital and has been in remission thus far. Adult liver transplantations from pediatric donors are feasible treatments. Systematic donor and recipient assessments, sound
\end{abstract}

Correspondence to: Dr Zhidan Xu, Department of Transplantation, Jiangxi Provincial People's Hospital Affiliated to Nanchang University, 152 Aiguo Road, Nanchang, Jiangxi 330000, P.R. China E-mail: xuzhidan1970@163.com

Key words: liver transplantation, organ donation, pediatric liver donors, postoperative complications surgical skills and optimal postoperative treatments are essential for success in the transplantation of livers from pediatric donors into adult recipients. Considering the condition of the donor liver, the selection of recipients and appropriate surgical methods are particularly important in these cases.

\section{Introduction}

Liver transplantation is widely accepted as an effective therapy for patients with end-stage liver disease (1). In the past, donor organs in China were mainly transplanted from relatives and deceased patients. With improvements in China's legal system, the use of deceased patients as donors was banned in $2015(2,3)$. As a consequence, there has been a severe shortage of organ donors (4). Organ transplantation from living relative donors has become the last resort; however, it is not advocated (4). After lengthy discussions and developments within the organ transplant branch of the Chinese medical association (5), donation after citizen's death (DCD) became the major source of organs for transplantation in 2015 (3). Pediatric DCDs account for a certain proportion of the total DCD donors (6). It is at times difficult to find matching child recipients for the organs of older-aged normally developed child donors (6). Therefore, liver transplantations in adults using pediatric donor livers have been performed to improve organ utilization (7-18). This has broadened the source of liver donors for transplantation in adults and certainly alleviated any shortages $(7,8)$. Selection of optimal recipients and appropriate surgical methods based on the condition of the donor liver (including donor liver volume, caliber difference between donor and recipient vessels, and the spatial location of the donor liver in the abdominal cavity of recipients, are crucial for successful liver transplantation in adults using pediatric donor livers (16-18). At present, pediatric donation in China is still in its infancy (9-15). The DCD donation process was implemented in the hospital of the current study during its initial development as a pilot project. In April 2008, a preliminary experience was obtained at the hospital with the first case of an adult liver transplantation using a pediatric donor liver (case 1 of the present study). Another two transplantations wherein child donors provided organs for liver transplantation in adults were performed in November 2015 (case 2) and May 2016 (case 3). In the present study, these three cases of adult liver transplantation using pediatric liver DCDs 
were discussed. The relevant points and challenges discussed include liver procurement and trimming, recipient selection, surgical tips, prevention and treatment of small-for-size syndrome (SFSS), selection of immunosuppressive regimens, prevention and treatment of vascular complications and anticoagulant therapy.

\section{Materials and methods}

Patients. The study was approved by the Ethics Committee of Jiangxi Provincial People's Hospital (Nanchang, China). Informed consent was obtained from the legal guardians of donors for use of their tissues and publication of associated data. Informed consent was obtained from the recipients for receiving pediatric donor tissue and publication of their data.

Pediatric donor data. Adult liver transplantations using pediatric donor livers were successfully performed in three cases at Jiangxi Provincial People's Hospital (Nanchang, China) between April 2008 and May 2016. A total of 3 pediatric donors (male, 2; female, 1; mean age, 8.67 years; age range, $8-10$ years, mean body mass index, $15.12 \pm 3.31 \mathrm{~kg} / \mathrm{m}^{2}$ ) were recruited between April 2008 and May 2016. Using the China Classification for Organ Donation (5), one donor was designated China Category I (organ donation consistent with international standards for donation following brain death) and the other two donors were designated China Category III (organ donation following brain death awaiting cardiac death). Of the three pediatric donors, one had died of a brain tumor and two had died of brain trauma. Age, sex and relevant laboratory indexes, including total bilirubin (TBIL), direct bilirubin (DBIL), aspartate aminotransferase (AST), alanine aminotransferase (ALT), serum creatinine, warm ischemia time, cold ischemic time and quality of the donor liver, were evaluated. All of these parameters were within normal limits (Table I). Following trimming, the graft/recipient weight ratio (GRWR) was 1.07-1.39\% and the graft volume/recipient standard liver volume ratio (GV/SLV) was $65.14-69.54 \%$.

Clinical data of liver transplant recipients and postoperative medications. A total of 3 liver recipients (male, 2; female, 1; mean age, 47.67 years; age range, 39-56 years) who were confirmed to have primary liver cancer were recruited between April 2008 and May 2016. The liver functions were graded as Child-Pugh A in two patients and Child-Pugh B in one patient (19). Two recipients underwent orthotopic liver transplantation and one underwent piggyback liver transplantation (Table II). Post-operatively, an immunosuppressive regimen consisting of mycophenolate mofetil and tacrolimus was scheduled for the recipients with primary hepatocellular carcinoma. Anti-HBV treatment was administered orally in the form of anti-HBV drugs. If necessary, anti-HBV drugs were recommended in combination with two antiviral drugs. Hepatitis B immunoglobulin was administered during the hospitalization. Post-operative anticoagulant therapies, including low molecular weight heparin sodium and aspirin, were administered according to the recipients' liver blood flow monitored by color Doppler ultrasound and associated coagulation function indicators.

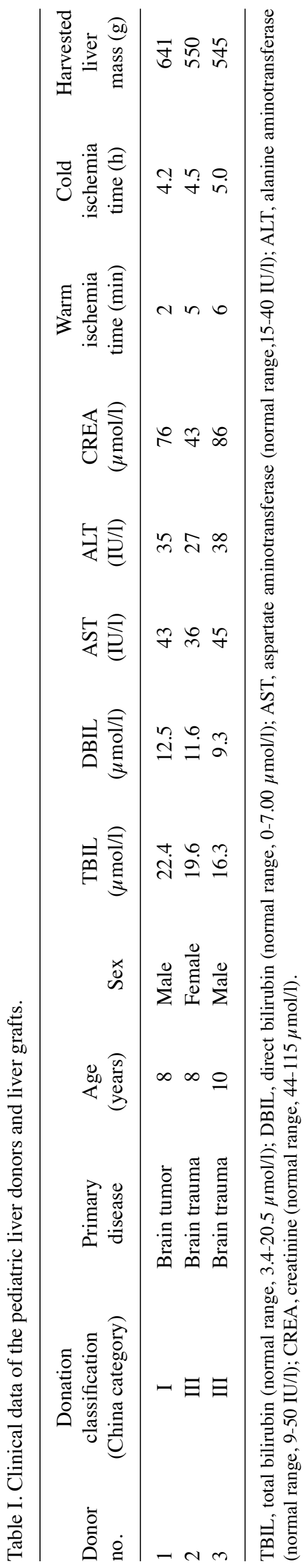


Table II. Clinical data of adult liver transplant recipients of pediatric donor livers.

\begin{tabular}{|c|c|c|c|c|c|c|c|c|c|}
\hline $\begin{array}{l}\text { Recipient } \\
\text { no. }\end{array}$ & Primary disease & $\begin{array}{c}\text { Age } \\
\text { (years) }\end{array}$ & Sex & $\begin{array}{l}\text { Body } \\
\text { height } \\
(\mathrm{cm})\end{array}$ & $\begin{array}{c}\text { Body } \\
\text { weight } \\
(\mathrm{kg})\end{array}$ & $\begin{array}{l}\text { Liver } \\
\text { function } \\
\text { grading }\end{array}$ & $\begin{array}{l}\text { Anhepatic } \\
\text { time (min) }\end{array}$ & $\begin{array}{l}\text { Surgical } \\
\text { mode }\end{array}$ & $\begin{array}{c}\text { Operation } \\
\text { time }(\mathrm{h})\end{array}$ \\
\hline 1 & Primary liver cancer & 39 & Female & 156 & 46 & Child B & 49 & Orthotopic & 6.1 \\
\hline 2 & Primary liver cancer & 56 & Male & 160 & 49 & Child A & 53 & Piggyback & 5.2 \\
\hline 3 & Primary liver cancer & 48 & Male & 162 & 51 & Child A & 58 & Orthotopic & 4.5 \\
\hline
\end{tabular}

Table III. Clinical data of recipient 2 following surgery.

\begin{tabular}{|c|c|c|c|c|c|c|c|c|c|}
\hline $\begin{array}{l}\text { Number } \\
\text { of days } \\
\text { after } \\
\text { surgery }\end{array}$ & $\begin{array}{c}\text { TBIL } \\
(\mu \mathrm{mol} / 1)\end{array}$ & $\begin{array}{c}\text { DBIL } \\
(\mu \mathrm{mol} / 1)\end{array}$ & $\begin{array}{l}\mathrm{AST} \\
(\mathrm{U} / \mathrm{l})\end{array}$ & $\begin{array}{l}\text { ALT } \\
(\mathrm{U} / 1)\end{array}$ & $\begin{array}{c}\text { PT } \\
(\mathrm{sec})\end{array}$ & $\begin{array}{c}\text { APTT } \\
(\mathrm{sec})\end{array}$ & INR & $\begin{array}{c}\text { Blood } \\
\text { ammonia } \\
(\mu \mathrm{mol} / \mathrm{l})\end{array}$ & $\begin{array}{c}\text { Depth of ascites in sitting } \\
\text { position monitored } \\
\text { by color Doppler } \\
\text { ultrasound }(\mathrm{cm})\end{array}$ \\
\hline 1 & 23.2 & 16.5 & 659 & 516 & 17.5 & 82.6 & 1.56 & 121.9 & 3.4 \\
\hline 3 & 80.3 & 65.1 & 316 & 266 & 15.2 & 45.9 & 1.34 & 61.2 & 2.2 \\
\hline 5 & 44.8 & 26.9 & 64 & 182 & 13.3 & 34.8 & 1.16 & 75.4 & 2.0 \\
\hline 7 & 42.5 & 23.3 & 3,431 & 4,588 & 21.0 & 36.3 & 1.89 & 108.5 & 4.2 \\
\hline 9 & 89.8 & 54.2 & 3,705 & 5,698 & 31.2 & 52.1 & 2.89 & 146.0 & 8.7 \\
\hline 11 & 86.1 & 50.2 & 1,853 & 5,135 & 20.9 & 39.4 & 1.88 & 125.7 & 5.2 \\
\hline 13 & 66.1 & 46.1 & $85 \mathrm{I}$ & 1,027 & 19.2 & 38.8 & 1.72 & 89.2 & 4.8 \\
\hline 15 & 45.9 & 30.5 & 43 & 443 & 16.5 & 43.4 & 1.46 & 44.6 & 3.3 \\
\hline
\end{tabular}

TBIL, total bilirubin; DBIL, direct bilirubin; AST, aspartate aminotransferase; ALT, alanine aminotransferase; PT, prothrombin time; APTT, activated partial thromboplastin time; INR, international normalized ratio.

\section{Results}

In the case of recipient 1 , postoperative jaundice worsened during the course of the hospital stay following transplantation. On the 3rd postoperative day, TBIL, DBIL, ALT and AST levels were up to 178, 93.9, $84.1 \mu \mathrm{mol} / \mathrm{l}, 153$ and $267 \mathrm{IU} / \mathrm{l}$, respectively, but the recipient had no chills or fever and no liver pain, and the T-tube drainage prevented bile leakage. Recipient 1 was considered to suffer from FK506 toxicity as the FK506 blood concentration was $12.66 \mathrm{ng} / \mathrm{ml}$ and there was no evidence of rejection. After reducing the FK506 dose, the TBIL level gradually decreased and the bile drainage volume gradually increased to $300-500 \mathrm{ml}$ per day. Recipient 1 was discharged around postoperative day 40 . The T-tube was clamped at 2 postoperative months and cholangiography was performed after 3 months of continuous clamping of the T-tube. The cholangiography results indicated normal biliary tract outflow, with no signs of obstruction and the T-tube was removed. Postoperative chemotherapy with 5-fluorouracil and calcium folinate was administered only once, as the white blood cell count was low after chemotherapy. In 2011, recipient 1 died of liver cancer recurrence and bone metastasis.

In the case of recipient 2 , on the 7 th postoperative day, the patient suddenly developed abdominal distension, prolongation of the clotting time and a sudden and dramatic rise in transaminase levels, which peaked on the 9th postoperative day. The TBIL, DBIL, ALT and AST levels were $89.8 \mu \mathrm{mol} / \mathrm{l}$,

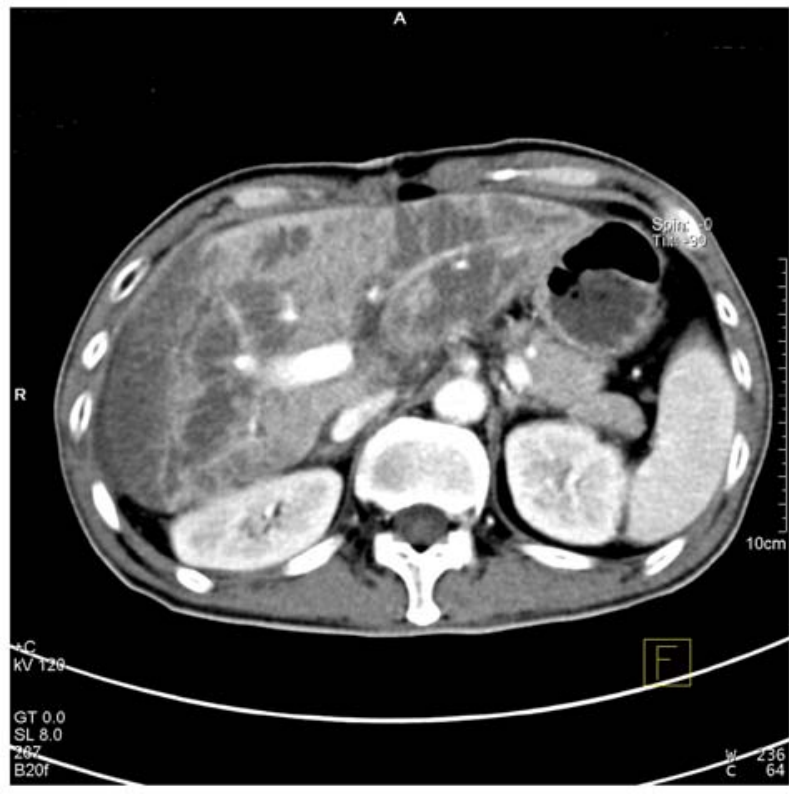

Figure 1. Multiple low-density lesions are visible on CT angiography in recipient 2 .

5,698 and 3,705 IU/1, respectively (Table III). The results of CT angiography revealed multiple low-density lesions in the liver and a weakly developed hepatic artery (Figs. 1 and 2). 


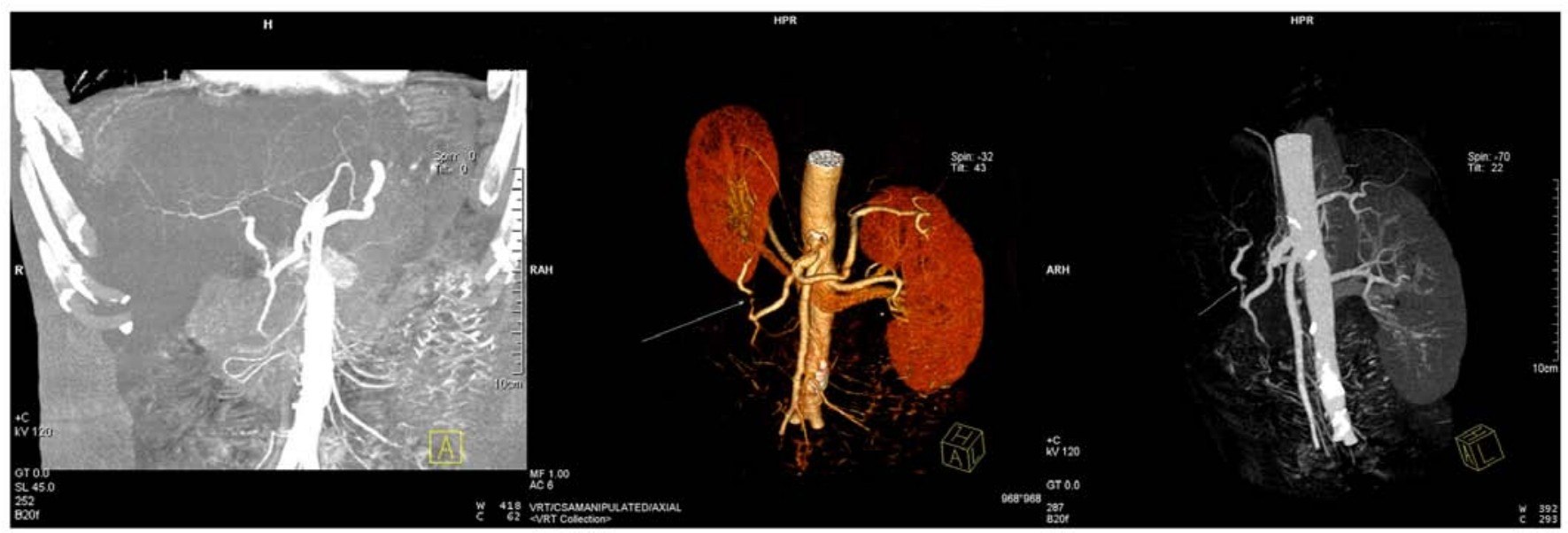

Figure 2. CT angiography in recipient 2 reveals that the hepatic artery was weakly developed on the 9th postoperative day. Images from the left to right are the coronal image and two angles of a three-dimensional reconstruction image.

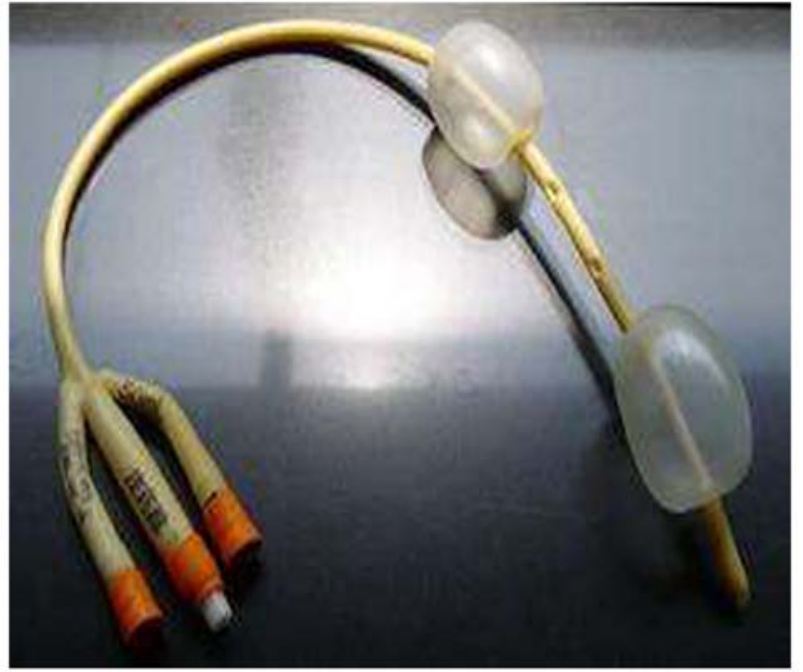

Figure 3. The abdominal drainage tubes with balloons. The internal diameter and length of the tube was $7.3 \mathrm{~mm}$ and $39 \mathrm{~cm}$, respectively.

Recipient 2 was diagnosed with avascular necrosis of the liver and the following measures were taken: Withdrawal or reduction of the dosages of the drugs considered to have caused the liver damage, adjustment of the dosage of the immunosuppressive agents, increasing the administration of antibacterial drugs and initiation of somatostatin and terlipressin to improve the blood supply to the liver. Thereafter, the clinical symptoms of recipient 2 improved significantly on the 13th postoperative day. He experienced a gradual recovery of his liver function and was then discharged from hospital. As of now, recipient 2 remains in remission and is subjected to regular follow-ups.

Recipient 3 recovered well after the liver transplantation and his liver function returned to normal on the 3rd postoperative day. Since his discharge from hospital, the patient has been in remission and is subjected to regular follow-ups.

\section{Discussion}

In the present study, three cases of adult liver transplantation using pediatric donor livers achieved good clinical results.
Pediatric donor livers have abundant blood vessels, little connective tissue, incomplete liver parenchyma, strong regenerative capacity and are unlikely to develop cirrhosis (20). Hepatocytes are basically mature at the age of 8 years (6) and there is still space for postoperative donor liver growth (9). Increased attention should be paid to the harvesting and trimming of the donor liver, the choice of recipients and the prevention and management of postoperative complications.

Regarding the procurement of donor livers, it should be observed during organ harvesting that the blood vessels and biliary tract in the livers of the pediatric donors, particularly those of underweight children, are thin (9,16-18). Therefore, a modified no. 10 suction tube may be used to achieve better perfusion instead of using a modified Foley catheter, which is generally used for adult abdominal aortae. The donor livers from underweight children are not necessarily mature and, therefore, the perfusion fluid should be maintained at a moderate level so to prevent excessive pressure that may cause liver sinus injury (10). Furthermore, the perfusion amount for pediatric donors is lower than that for adult donors (9). Care must be taken to avoid overperfusion while still ensuring adequate donor perfusion (16). In the present study, during the harvesting of the donor liver, the perfusion height for the pediatric donor was 10-20 cm lower than that for the adult donor and the perfusion amount for the pediatric donor was $1 / 2$ to $2 / 3$ of that of the adult donor to reduce perfusion damage to the donor liver.

During the trimming of the donor livers, the pediatric donor liver used in adult liver transplantation should be strictly assessed to avoid small-for-size donor livers (21-24). The small-sized pediatric liver grafts may easily shift in the abdominal cavity, causing the blood vessels and biliary tract to be distorted (21-24). Therefore, during trimming of donor livers, a part of the sacral ligament may be retained to fix the donor liver after surgery. As the wall of the inferior vena cava in the pediatric liver is thinner, the surrounding tissue does not require to be completely separated (21). Otherwise, blood oozing may easily occur during and after surgery (21). The hepatic artery in the pediatric liver is slender and complete trimming is not required (22). This reduces the probability of vascular embolism caused by intimal injury during 
manipulation $(22,23)$. Special trimming of the common bile duct is not generally required, which may be severed directly at the edge of the pancreas to avoid interruption of the blood supply (24).

Regarding the choice of recipients, patients with tumors as the primary disease and those with lower body weights are considered to be the optimal recipients in adult liver transplantation using pediatric donor livers $(11,16-18)$. Patients who have had $>1$ episode of gastrointestinal bleeding, multiple previous surgeries and/or severe portal hypertension are not considered ideal candidates for pediatric liver transplantations (11). In the present study, the body masses of recipients 1,2 and 3 were all under $60 \mathrm{~kg}$ and their primary disease was primary liver cancer. Preoperative liver function was graded as Child-Pugh A in two cases and Child-Pugh B in one case. Therefore, the postoperative incidence of SFSS was effectively reduced. In addition, the donor GV/SLV may be used as a selection criterion to assess the size matching between the liver graft and the recipient. GV may be measured by CT or directly by the water displacement method. SLV may be measured using the following formula: $\mathrm{SLV}(\mathrm{ml})=706.2 \mathrm{x}$ body surface area $\left(\mathrm{BSA}, \mathrm{m}^{2}\right)+2.4(25)$, BSA of pediatric donor $\left(\mathrm{m}^{2}\right)=0.0061 \mathrm{x}$ body height $(\mathrm{BH}, \mathrm{cm})+0.0128 \mathrm{x}$ body weight (BW, $\mathrm{kg}$ ) -0.1529 and BSA of adult recipient $\left(\mathrm{m}^{2}\right)=0.00659 \mathrm{x}$ BH $(\mathrm{cm})+0.0126 x$ BW $(\mathrm{kg})-0.1603$ (4). The GRWR may be calculated according to the conversion of weight to volume by the conversion factor of $1.19 \mathrm{ml} / \mathrm{g}(26)$. The currently accepted standard is that GV/SLV should be $>40 \%$ (27) and GRWR should not be $<0.8-1 \%$ (28). In the present study, the GV/SLV was $65.14-69.54 \%$ and the GRWR was $1.07-1.39 \%$.

Orthotopic or piggyback adult liver transplantations from pediatric donors may be advantageous (9,16-18). The choice of orthotopic liver transplantation falls in line with the physiological requirements of the human body $(9,16-18)$. Therefore, considering the relatively small size of the pediatric donor liver, the first porta hepatis (portal vein, hepatic artery and the common bile duct) should be isolated carefully to preserve the adequate length and the blood supply of the biliary tract. Since the adult recipient has a larger abdominal cavity relative to the child donor, orthotopic liver transplantations are relatively better with respect to fixation of the donor liver and they impart a lower risk of vascular complications such as outflow obstruction (9). The use of piggyback liver transplantations may avoid vena cava stenosis caused by the differences in the vena cava diameters and reduce the surgical complications caused by the blood vessel mismatches in the donor liver (29). During liver trimming, the donor hepatic artery may be trimmed using vascular loops for anastomosis in order to solve the mismatch with the caliber of the hepatic artery (11,21-24). For the anastomosis of the common bile duct between the donor and recipient, continuous anastomosis of the posterior wall and intermittent anastomosis of the anterior wall have been adopted (11). Furthermore, a T-tube may be placed to guide the drainage if a significant difference exists in the calibers of the common bile ducts of the donor and the recipient (30). When entering the blood vessels, controlling the blood pressure is necessary to reduce damage to the donor liver (9). In the present study, orthotopic liver transplantation was performed in two cases as there were no significant differences in the vena cava calibers between the recipients and donors. The ligaments of the donor livers and the abdominal drainage tubes with balloons placed around the livers were used in all three cases to fix the liver grafts in the abdominal cavities (Fig. 3) . This effectively reduced the blood vessel and biliary tract distortions caused by position changes in the transplanted livers.

SFSS prevention is key in adult liver transplantations using pediatric donor livers $(31,32)$. The mechanism underlying SFSS is that excessive perfusion of the portal vein causes mechanical injury to the hepatic sinus and portal vein endothelial cells, destruction of the space of Disse, as well as flaky necrosis of liver tissues $(17,33)$. During liver transplantation in an adult using a pediatric donor liver, effective control of the blood flow in the portal vein may significantly reduce the risk of SFSS in adult recipients (34-37). To reduce postoperative portal venous pressure, intraoperative ligation of the splenic artery or splenectomy may be considered and a postoperative intravenous infusion of somatostatin or terlipressin may also be administered according to the unique situation of the patient (38-40). In the present study, on the 7th postoperative day, recipient 2 experienced sudden abdominal distension, developed a prolongation of the clotting time and exhibited a sudden and marked rise in the level of transaminase that peaked on the 9th postoperative day. Postoperative TBIL, DBIL, ALT and AST levels in recipient 2 were $89.8 \mu \mathrm{mol} / 1$, 5,698 and 3,705 IU/1, respectively. CT angiography revealed multiple low-density lesions in the liver and a weakly developed hepatic artery. Recipient 2 was thus diagnosed with avascular necrosis of the liver, in line with the manifestations of SFSS. Somatostatin and terlipressin were administered to improve the blood supply in the liver. On the 13th postoperative day, the patient's clinical symptoms improved significantly. The patient exhibited a gradual improvement in liver function and was then discharged from hospital. These observations indicate that the ability of pediatric donor liver cells to regenerate is stronger than that of adults; transplant liver function and postoperative growth are issues of concern in adult liver transplantations using pediatric donors (41). Postoperative administration of terlipressin effectively alleviates high portal venous pressure, reduces hepatic blood flow and eases the mechanical damage to the liver sinuses. The early rise in portal venous pressure is specifically controlled to avoid dual injury from excessive perfusion and ischemia-reperfusion (42). This postoperative treatment provides a novel method for effective prevention and treatment of SFSS after liver transplantation $(42,43)$. Terlipressin administration should not be prolonged. Close monitoring of the patient's vital signs and routine color Doppler ultrasound of the transplanted liver are necessary to reduce the incidence of portal vein thrombosis and bradycardia.

The use of immunosuppressive agents is key to prevent rejection after liver transplantation. Tacrolimus is mainly metabolized via the cytochrome P450 system in the liver and small intestine and is then excreted via the biliary tract (44-47). The use of immunosuppressive agents after liver transplantation in an adult using a pediatric donor liver cannot be generalized. Considering the smaller size of the donor liver in case 1, the ability of the donor liver to metabolize the immunosuppressive agents was less effective than that of the adult liver and therefore, the FK506 blood concentration was maintained at a lower level than the standard value. Combined with the 
results from cases 2 and 3 in the present study and the results of previous studies (48-50), it was indicated that pediatric donor livers have higher clearance rates for tacrolimus and therefore, the dose of tacrolimus for pediatric donors should be 2-4 times that of adult donors to achieve the same concentration. This is inconsistent with the conclusion obtained in case 1 of the present study. Therefore, individualization of tacrolimus dosing is required after liver transplantation in an adult using a pediatric donor liver $(51,52)$.

Regarding the prevention and treatment of vascular complications and anticoagulation therapy, vascular complications associated with liver transplantation in adults using a pediatric donor liver are mainly triggered by blood vessel volume mismatches between donors and recipients (10). Furthermore, high portal perfusion pressures may easily cause reactive contractions of hepatic arterioles, which reduces the arterial blood flow and may potentially cause the formation of a thrombus (9,16-18). Anticoagulant therapy is given according to blood flow monitoring on color Doppler ultrasound and laboratory indicators (8). In the present study, early postoperative administration of low molecular weight heparin, warfarin and aspirin anticoagulation was initiated to prevent hepatic artery thrombosis. The anticoagulant drugs were adjusted or stopped in accordance with the follow-up results from 3-6 months postoperatively.

In conclusion, the present study suggested that liver transplantations in adults using pediatric donor livers are feasible. Systematic donor and recipient assessments, sound surgical skills and optimal postoperative management are essential for success in adult liver transplantations using pediatric donor livers. Adult liver transplantations using pediatric donor livers can widen the pool of liver donors for adult transplantation and certainly alleviate the source shortage. Considering the condition of the donor liver, selection of recipients and appropriate surgical methods are particularly important for adult liver transplantations using pediatric donor livers.

\section{Acknowledgements}

Not applicable.

\section{Funding}

The current work was supported by grants from Key R\&D Project of Scientific and Technical Supporting Program of Jiangxi Province (grant no. 20161BBG70121) and the Science and Technology Planning Project of Health and Family Planning Commission of Jiangxi Province (grant no. 20181006).

\section{Availability of data and materials}

The datasets used and/or analyzed during the current study are available from the corresponding author on reasonable request.

\section{Authors' contributions}

LDi designed the study, analyzed and interpreted data and wrote the manuscript. LDe and XL collected, analyzed and interpreted data. ZX designed the study and critically revised the manuscript. All authors read and approved the final manuscript.

\section{Ethics approval and consent to participate}

The current study was approved by the Ethics Committee of Jiangxi Provincial People's Hospital (Nanchang, China). Written informed consent was obtained from the legal guardians of donors for use of their tissues and publication of associated data. Written informed consent was obtained from the recipients for receiving pediatric donor tissue and publication of their data.

\section{Patient consent for publication}

Not applicable.

\section{Competing interests}

The authors declare that they have no competing interests.

\section{References}

1. Chen ZH: New sight after a quarter century: A long Chinese way to tackle the organ shortage in the era of worldwide organ crises. Zhonghua Yizhi Zazhi Diziban 4: 265-272, 2010.

2. Zhang L, Zeng L, Gao X, Wang H and Zhu Y: Transformation of organ donation in China. Transpl Int 28: 410-415, 2015.

3. Zhang GY, Liao T, Fu XB and Li QF: Organ transplantation in China: Concerns remain. Lancet 385: 854-855, 2015.

4. Yan LN: Modern Liver Transplantation. 1st edition. Beijing, Military science publishing house, pp292-306, 2004.

5. Organ Transplantation Branch of the Chinese Medical Association. National guidelines for donation after cardiac death in China (2nd edition). Zhonghua Qiguanyizhi Zazhi 32: 756-758, 2011.

6. Shen XM: Clinical Pediatrics. 1st edition. People's Medical Publishing House, Beijing, pp1010-1011, 2005.

7. Werner MJM, van Leeuwen OB, de Jong IEM, Bodewes FAJA Fujiyoshi M, Luhker OC, Scheenstra R, de Vries Y, de Kleine RHJ and Porte RJ: First report of successful transplantation of a pediatric donor liver graft after hypothermic machine perfusion. Pediatr Transplant 23: e13362, 2019.

8. Croome KP, Lee DD, Burns JM, Saucedo-Crespo H, Perry DK, Nguyen JH and Taner CB; Mayo Clinic Collaborative in Transplant Research and Outcomes: Outcomes of liver transplantation with liver grafts from pediatric donors used in adult recipients. Liver Transpl 22: 1099-1106, 2016.

9. He XS, Ju WQ, Guo ZY, Wu LW, Tai Q, Han M, Wang DP, Zhu XF and Huang JF: First case of pediatric donor liver for adult liver transplantation in China. Zhonghua Waike Zazhi 48: 1597-1598, 2010.

10. Shi J, Luo WF, Ding LM, Xu ZD, Wang YG, Li XC, Luo LB and Long CM: Clinical analysis of liver transplant from a child of brain death to an adult. Zhonghua Gandan Waike Zazhi 17: 359-363, 2011.

11. Wei L, Zhu ZJ, Dong C, Gao W, Yang T, Sun LY, Qu W, Rao W, Sun XY and Shen ZY: Use of liver graft from pediatric donor of donation after cardiac death in adult recipient (report of one case). Zhongguo Puwai Jichu Yu Linchuang Zazhi 19: 490-492, 2012.

12. Huang XL, Li GQ, Mu XX, Qin JJ, Zhou S, Li MY, Pang XX, Tan SB and Sun PC: Preliminary experience of pediatric donor liver and advanced marginal donor liver in adult liver transplantation. Nanjing Yike Daxue Xuebao (Ziranban) 36: 193-196, 209, 2016.

13. Lan C, Song JL, Yan LN, Yang JY, Wen TF, Li B and Xu MQ: Pediatric donor to adult recipients in donation after cardiac death liver transplantation: A single-center experience. Transplant Proc 49: 1383-1387, 2017. 
14. Ju W, Li C, Zhang C, Ko DS, Wang D, Han M, Schroder PM, Wang X, Jiao X, Wu L, et al: Outcome of the use of paediatric donor livers in adult recipients: A single Chinese Centre experience. Clin Res Hepatol Gastroenterol 43: 148-154, 2019.

15. Li JJ, Zu CH, Li SP, Gao W, Shen ZY and Cai JZ: Effect of graft size matching on pediatric living-donor liver transplantation at a single center. Clin Transplant: 32, 2018. doi: 10.1111/ctr.13160.

16. Yasutomi M, Harmsmen S, Innocenti F, DeSouza N and Krom RA: Outcome of the use of pediatric donor livers in adult recipients. Liver Transpl 7: 38-40, 2001.

17. Emre S, Soejima Y, Altaca G, Facciuto M, Fishbein TM, Sheiner PA, Schwartz ME and Miller CM: Safety and risk of using pediatric donor livers in adult liver transplantation. Liver Transpl 7: 41-7, 2001.

18. Zhang R,Zhu ZJ, Sun LY, Wei Land Qu W: Outcomes of liver transplantation using pediatric deceased donor livers: A single-center analysis of 102 donors. Chin Med J (Engl) 131: 677-683, 2018.

19. Pugh RN, Murray-Lyon IM, Dawson JL, Pietroni MC and Williams R: Transection of the oesophagus for bleeding oesophageal varices. Br J Surg 60: 646-649, 1973.

20. Shore PM, Huang R, Roy L, Darnell C, Grein H, Robertson T and Thompson L: Potential for liver and kidney donation after circulatory death in infants and children. Pediatrics 128: e631-e638, 2011.

21. Gu L, Fang H, Li F, Zhang S, Shen C and Han L: Impact of hepatic arterial hemodynamics in predicting early hepatic arterial thrombosis in pediatric recipients younger than three yr after living donor liver transplantation. Pediatr Transplant 19: 273-278, 2015.

22. Ackermann O, Branchereau S, Franchi-Abella S, Pariente D, Chevret L, Debray D, Jacquemin E, Gauthier F, Hill C and Bernard O: The long-term outcome of hepatic artery thrombosis after liver transplantation in children: Role of urgent revascularization. Am J Transplant 12: 1496-503, 2012.

23. Gu LH, Fang H, Li FH, Li P, Zhu CX, Zhu JJ and Zhang SJ: Prediction of early hepatic artery thrombosis by intraoperative color Doppler ultrasound in pediatric segmental liver transplantation. Clin Transplant 26: 571-576, 2012.

24. Guo WZ, Zhang JK, Cao SL, Wang ZH, Wen PH, Shi XY, Yang H, Chen CQ and Zhang SJ: Experience of pediatric organ procurement and bench surgery from donation after citizen's death. Shiyong Qiguan Yizhi Dianzi Zazhi 5: 11-14, 2017.

25. Urata K, Hashikura Y, Ikegami T, Terada M and Kawasaki S: Standard liver volume in adults. Transplant Proc 32: 2093-2094, 2000.

26. Chan SC, Liu CL, Lo CM, Lam BK, Lee EW, Wong Y and Fan ST: Estimating liver weight of adults by body weight and gender. World J Gastroenterol 12: 2217-2222, 2006.

27. Shimada M, Ijichi H, Yonemura Y, Harada N, Shiotani S, Ninomiya M, Yoshizumi T, Soejima Y, Suehiro T and Maehara Y: Is graft size a major risk factor in living-donor adult liver transplantation? Trans Int 17: 310-316, 2004

28. Lee HH, Joh JW, Lee KW, Kim SJ, Lee DS, Park JH, Choi SH, Heo JS, Hyon WS, Kwak MS and Lee SK: Small-for-size graft in adult living-donor liver transplantation. Transplant Proc 36 2274-2276, 2004.

29. Tannuri U, Mello ES, Carnevale FC, Santos MM, Gibelli NE, Ayoub AA, Maksoud-Filho JG, Velhote MC, Silva MM, Pinho ML, et al: Hepatic venous reconstruction in pediatric living-related donor liver transplantation-experience of a single center. Pediatr Transplant 9: 293-298, 2005.

30. Yang DS, Chen JJ, Lu Q, Huang ZY and Yang GD: Complicated bile duct stricture and its surgical treatment. Zhonghua Gandan Waike Zazhi 9: 73-75, 2003.

31. Tanaka K and Ogura Y: 'Small-for-size graft' and 'small-for-size syndrome' in living donor liver transplantation. Yonsei Med J 45: 1089-1094, 2004.

32. Marcos A: Right lobe living donor liver transplantation: A review. Liver Transpl 6: 3-20, 2000.

33. Adam R, Castaing D and Bismuth $\mathrm{H}$ : Transplantation of small donor livers in adult recipients. Transplant Proc 25: 1105-1106, 1993.

34. Gondolesi GE, Florman S, Matsumoto C, Huang R, Fishbein TM, Sheiner PA, Schwartz ME, Emre S, Thung S, Shapiro R and Miller CM: Venous hemodynamics in living donor right lobe liver transplantation. Liver Transpl 8: 809-813, 2002.
35. Man K, Lo CM, Ng IO, Wong YC, Qin LF, Fan ST and Wong J: Liver transplantation in rats using small-for-size grafts: A study of hemodynamic and morphological changes. Arch Surg 136: $280-285,2001$

36. Hill MJ, Hughes M, Jie T, Cohen M, Lake J, Payne WD and Humar A: Graft weight/recipient weight ratio: How well does it predict outcome after partial liver transplants? Liver Transpl 15: 1056-1062, 2009

37. Campos BD and Botha JF: Strategies to optimize donor safety with smaller grafts for adult-to-adult living donor liver transplantation. Curr Opin Organ Transplant 17: 230-234, 2012.

38. Zhang YH, Zhang R and Xu J: Clinical observation for hemodynamic changes of children DCD donor liver in adult recipients during early stage. Shiyong Qiguan Yizhi Dianzi Zazhi 5: 359-362, 2017.

39. Mack DR, Traystman MD, Colombo JL, Sammut PH, Kaufman SS, Vanderhoof JA, Antonson DL, Markin RS, Shaw BW Jr and Langnas AN: Clinical denouement and mutation analysis of patients with cystic fibrosis undergoing liver transplantation for biliary cirrhosis. J Pediatr 127: 881-887, 1995.

40. Noble-Jamieson G, Valente J, Barnes ND, Friend PJ, Jamieson NV, Rasmussen A and Calne RY: Liver transplantation for hepatic cirrhosis in cystic fibrosis. Arch Dis Child 71: 349-52, 1994.

41. Song YW, Zhu ZJ, Sun LY, Wei L, Qu W, Zeng ZG and Liu Y: Clinical study on growth and development of children after liver transplantation. Qiguan Yizhi: 235-239, 2015.

42. Li LB, Chen YM, Zhang SN, Gao Y, Ren G, Zhang CP, Xiong G and Ma J: Combination of terlipressin and FK409 for protection against small-for-size syndrome in living donor liver transplantation. Zhongwai Jiankang Wenzhai: 25-27, 2014.

43. Mo LQ, Yuan BL, Xiao Y, Xiao LC, Xu KQ and Huang WQ: Effects of terlipressin on hemodynamics and renal function in cirrhotic patients undergoing orthotopic liver transplantation. Shiyong Yixue Zazhi 23: 2461-2463, 2007.

44. Fung JJ and Starzl TE: FK506 in solid organ transplantation. Ther Drug Monit 17: 592-595, 1995.

45. Spada M, Corno V, Colledan M, Segalin A, Lucianetti A, Torre G, Riva S, Sonzogni A, Petz W and Gridelli B: Rejection and tacrolimus conversion therapy in paediatric liver transplantation. Transpl Int 13 (Suppl 1): S341-S344, 2000.

46. van Hooff JP and Christiaans MH: Use of tacrolimus in renal transplantation. Transplant Proc 31: 3298-3299, 1999.

47. Crespo-Leiro MG: Tacrolimus in heart transplantation. Transplant Proc 35: 1981-1983, 2003.

48. Yan LZ, Chen L, Wang LJ and Lu YX: Metabolic differences between tacrolimus in adult and child carcasses and living donor liver transplant recipients. Wujing Houqin Xueyuan Xuebao (Yixueban) 23: 578-582, 2014.

49. Neuhaus P, Blumhardt G, Bechstein WO, Platz KP, Jonas S, Mueller AR, Langrehr JM, Lohmann R, Schattenfroh N, Knoop M, et al: Comparison of FK506- and cyclosporine-based immunosuppression in primary orthotopic liver transplantation. A single center experience. Transplantation 59: 31-40, 1995.

50. Flanagan WM, Corthésy B, Bram RJ and Crabtree GR: Nuclear association of a T-cell transcription factor blocked by FK-506 and cyclosporin A. Nature 352: 803-807, 1991.

51. Ameyaw MM, Regateiro F, Li T, Liu X, Tariq M, Mobarek A, Thornton N, Folayan GO, Githang'a J, Indalo A, et al: MDR1 pharmacogenetics: Frequency of the C3435T mutation in exon 26 is significantly influenced by ethnicity. Pharmacogenetics 11: 217-221, 2001.

52. Jain A, Venkataramanan R, Sharma R, Kwong T, Orloff M, Abt P, Kashyap R, Tsoulfas G, Batzold P, Williamson M and Bozorgzadeh A: Pharmacokinetics of tacrolimus in living donor liver transplant and deceased donor liver transplant recipients. Transplantation 85: 554-560, 2008.

This work is licensed under a Creative Commons Attribution-NonCommercial-NoDerivatives 4.0 International (CC BY-NC-ND 4.0) License. 